\title{
INTRODUCTION \\ Kritika Kultura Special Issue on Cultural Practices and Policies in the Digital and Global Age
}

\author{
Patrick Messerlin \\ Sciences Po Paris \\ patrick.messerlin@gmail.com \\ Hwy-Chang Moon \\ Seoul School of Integrated Sciences and Technologies \\ cmoon.snu@gmail.com
}

\begin{abstract}
About the Authors
Patrick Messerlin is Professor Emeritus of economics at Sciences Po Paris, and Chairman of the Steering Committee of the European Centre for International Political Economy (ECIPE) in Brussels. He was senior economist at the World Bank and special advisor to Mike Moore, WTO Director General. He served as co-chair, with Ernesto Zedillo, former President of Mexico, of the United Nations Millennium Development Goals Task Force on Trade for Development, and as Chair of the Global Trade Council 2010-2011 of the World Economic Forum. He was visiting professor at the University of Houston, Texas; Simon Fraser University, Vancouver, Canada; Wolfgang Goethe-Universität, Frankfurt am Main, Germany; and at the Graduate School of International Studies, Seoul National University, Korea. His current research deals with economic and trade relations between Europe and East Asia, with a particular focus on cultural industries.
\end{abstract}

Hwy-Chang Moon is Chair Professor of Seoul School of Integrated Sciences and Technologies and Professor Emeritus of the Graduate School of International Studies at Seoul National University, where he also served as the Dean. He has delivered special lectures at various institutions, including Helsinki School of Economics, Keio University, and Stanford University. He is currently the editor-in-chief of the Journal of International Business and Economy, and he has published numerous journal articles and books on topics covering International Business Strategy, Cross-Cultural Management, Foreign Direct Investment, and Economic Development in East Asia with a focus on Korea. He has also served as consultant for several multinational companies, international organizations, and governments. 
Kritika Kultura and the European Centre for International Political Economy (ECIPE) are pleased to publish this special issue on cultural practices and cultural policies in the global and digital age. It is the outcome of a conference held in Ateneo de Manila University which has offered great opportunities for authors coming from different continents to discuss the vast changes in these domains.

This Special Issue was organized in order to shed new light on the cultural industries by offering diverse and innovative perspectives regarding their sustainability amongst the fast-changing environment in the global and digital age. Over the past several decades, various cultural industries-in particular, film and music on which this issue concentrates because of their cultural impact and economic importance-have increasingly been engaged by various governments, businesses, and institutions as strategic industries to improve consumers' life and strengthen the national image of the country they come from. With many promises and hopes, the cultural industries brought great opportunities for some nations and businesses, however, there remain problems and challenges for many as well, particularly with the ongoing vast spread of globalization and digitization. In many cases, governments and firms have responded differently to the volatile cultural and business environment and experienced different consequences. To illustrate and analyze the diverse situations, this Special Issue has six themes that incorporate key actors and factors from micro (e.g., technology, firm) to macro (e.g., government, international institution) and cover diverse topics from business, policy, and the humanities.

The first theme deals with the most basic aspect of such volatility-the adoption process of the "best" production technology. Retrospectively, this choice seems "obvious" to many observers. In fact, it is rarely the case, and the final outcome is often the result of a bumpy trial and error process. Jimmyn Parc's "Between Technological Advancement and Protectionism" (on MP3) and Stephen Ranger's "Adapting to Technological Changes in the Music Business" (on the music disk) offer fascinating insights into the difficulty of predicting and revealing the winning technology, and how much it generates conflicts among firms. Eventually, this makes the "winning firm" even more remarkable. In this process, mistakes should be expected, and what counts the most is the capacity to react and the energy to rebound swiftly.

The second theme also deals with the production process, but it shifts the focus on the role of firms and individuals in deepening and broadening the competitiveness in the production operations. For this matter, firms are examined more rigorously because they are the value creators that facilitate the spread of cultural products and services in the market. An examination of the value chain is a popular method where it allows for a simple demonstration of the increasing breadth of the value 
chain (e.g., internationalization), its depth (e.g., specific activities within the value creating activities such as vloggers), and its complexity (e.g., network among value chains). Sébastien Miroudot's "Hallyuwood" carries out an empirical research on the global value chain of the economic determinants of the Korean film industry in order to assess how the international production of Korean films is. Yeon W. Lee and Kuychan Kim's “The Next Growth Strategy for Hallyu” also examines the entire value chain activities of the firms by paying attention to the global large enterprises that have larger and more extensive value creating platforms which increase the scope and scale for other firms to network in the film industry. In "A New Model for Globalization in the Film Industry," Wenyan Yin utilizes the value chain as the tool to understand the logic of co-production, applying it to the "denationalizing" process of the Chinese film industry. Lastly, Jin Sup Jung and Min Jae Lee's "SStrategy for the Cultural Contents Industry to Secure Competitive Advantage Using Fourth Industrial Revolution Technology" expands the scope of industries to other cultural contents industries with a focus on the fourth industrial revolution technology.

The third theme of this Special Issue examines the production factors per se, such as actors, authors, engineers, "vloggers," and fans who emerge as key components in the increasingly long and sophisticated modern value chains. Hee Jun Kim, Maxime Martigane, and Jimmyn Parc's "Assessing the Impact of Protectionism upon the Performance of Actors" compares the performance of actor-director in various countries and relates it to the level of subsidies from both domestic and international (e.g., co-production) perspectives. Holger Schwetter's "From Record Contract to Artrepreneur" examines the changing preferred career management system of musicians by drawing a comparison between record contract and selfmanagement ("artepreneur"). Sangkyu Lee's "Deepening Conditions of Precarity in the Korean Game Industry" examines the changing situation and role of the engineers in the game industry as this sector has evolved from PC online to mobile game platforms, with its structural, managerial constraints for further growth. Yeon W. Lee's "Synergistic Co-operations in the Cosmetic Industry" links the process of production with the social media contents where vloggers carry out differentiated roles from the past in enhancing the competitiveness of the firms. WoongJo Chang and Shin-Eui Park's "The Fandom of Hallyu" focuses on fandom as another important and active contributor to the success of cultural contents by integrating the perspectives from the humanities and anthropology. Lastly, Nissim Otmazgin and Irina Lyan's "Fan Entrepreneurship" analyzes the role of fans as the new form of entrepreneurs in facilitating foreign culture by examining Hallyu in Israel.

The fourth theme of this Special Issue shifts to macro-economic perspectives by underlining some important conditions which may serve as the prerequisites 
for successful growth in the cultural industry. Hwy-Chang Moon's "Increasing Opportunity and Value in the Cultural Industries," examines the key role of clusters in strengthening and expanding the scope of the cultural industries. This paper compares the successful clusters of Renaissance and Hollywood to draw comparison to the potential sustainability of Hallyu as its growth is more based on firms than on geographic concentration. Man-Soo Cho's "The Industrialization of Korea's Performing Arts and Its Path for Globalization" suggests how the Japanese market possesses the mature consumer infrastructure to make Hallyu prosper, and discusses the importance of key resources and systems outside the firms' boundary. Lastly, Xiaolan Zhou's “How Industrial Policies Shaped the Globalization of the Chinese Film Industry" introduces the role and structure of government support as the prerequisite for success and discusses how sophistication could be achieved in China's film industry.

The fifth theme focuses on providing meaningful insights onto the broader reflections of the cultural industry. The four papers have different scopes and topics, but they are in unison in their idea to seek an "optimal" balance for sustainable cultural industry. They offer much more nuanced views than the black and white dichotomy of perspectives which often prevail in the existing literature of cultural policies. Patrick Messerlin's “Building Consistent Policies on Subsidies in the Film Industry" looks for an "optimal" design of institutions in charge of the film industry development by comparing France's CNC and Korea's equivalent institution, KOFIC. In "Does Copyright Help or Harm Cultural Diversity in the Digital Age?", Sean Pager provides a nuanced understanding of copyright law, and draws lessons for a balanced copyright regime to cope with the advent of digital technology. Lastly, Jimmyn Parc and Hwy-Chang Moon's "Accumulated and Accumulable Cultures" distinguishes accumulated and accumulable cultures which offer a good basis to provide important implications for policy makers to formulate effective policies that will help promote their national culture as a source of soft power.

Finally, the sixth theme of this Special Issue deals with new possible roles of government. In “Japan's Soft Power and 'Grand Fictions' in Global Venues," Marco Pellitteri shows how the Japanese government tries to act as the mobilizer of culture in the international stage by carrying out a specific function through the Olympics in an effort to enhance its soft power. Sunhee Park's "The Evolution of the Concept and Practical Application of Cultural Diversity in Korea" takes an even broader approach to cultural practices and industries by examining the potential role of the UNESCO cultural diversity concept in the transition process into a more multicultural Korean society.

The six themes of this Special Issue are organized and orchestrated in order to provide meaningful academic insights from micro and macro levels. From 
technologies to firms, governments, and international organizations, this Special Issue covers extensive approaches by touching on the key players of culture while also rendering new directions for sustainability in the cultural industry which is multi-faceted in nature. As a strategic industry with immeasurable potentials for other industry development, this Special Issue thoroughly examines earlier literature while adding important improvements in the hope of contributing to the betterment of the cultural industry in both academic and practical fields.

For the publication of this Special Issue, we would first like to express our warmest gratitude to Prof. Maria Luisa Torres Reyes, Editor Emerita of Kritika Kultura and Scholar-in-Residence of the University of Santo Tomas, for her strong support to this endeavor since its very beginning. We would like to extend our deepest gratitude to the Editor-in-Chief of Kritika Kultura, Dr. Vincenz Serrano, for his unfaltering dedication to publish this joint Special Issue and organize the conference in Ateneo de Manila University. We would also like to thank Francis Sollano and Dr. Alona U. Guevarra of Kritika Kultura for their efficient collaborative efforts in the various stages of publication, and finally the Ateneo de Manila University for hosting us with impeccable logistics. Last but not the least, we would like to express our profound gratitude to Dr. Jimmyn Parc for the intellectual input, energy, and time he invested in the whole endeavor from beginning to end.

Our further expression of gratitude goes to the Academy of Korean Studies (AKS) for supporting our research on culture including important topics on Hallyu, cultural policy, and business perspectives to culture. Lastly, we would like to thank ECIPE for all its professional and managerial support. To every individual and organization including the authors and all other participants, we send our appreciation and gratitude. 